\title{
Synthesis and Molecular Docking of Some Grossgemin Amino Derivatives as Tubulin Inhibitors Targeting Colchicine Binding Site
}

\author{
R. I. Jalmakhanbetova, ${ }^{1}$ Eslam B. Elkaeed ${ }^{D},{ }^{2}$ Ibrahim H. Eissa $\left(\mathbb{D},{ }^{3}\right.$ Ahmed M. Metwaly $\left(\mathbb{D},{ }^{4}\right.$ \\ and Ye. M. Suleimen iD ${ }^{5}$ \\ ${ }^{1}$ Kazakh University of Technology and Business, Nur-Sultan 010008, Kazakhstan \\ ${ }^{2}$ Department of Pharmaceutical Sciences, College of Pharmacy, AlMaarefa University, Ad Diriyah, Riyadh 13713, Saudi Arabia \\ ${ }^{3}$ Pharmaceutical Medicinal Chemistry \& Drug Design Department, Faculty of Pharmacy (Boys), Al-Azhar University, \\ Cairo 11884, Egypt \\ ${ }^{4}$ Pharmacognosy and Medicinal Plants Department, Faculty of Pharmacy (Boys), Al-Azhar University, Cairo, Egypt \\ ${ }^{5}$ Sh. Ualikhanov Kokshetau University, Kokshetau 020000, Kazakhstan
}

Correspondence should be addressed to Ahmed M. Metwaly; ametwaly@azhar.edu.eg and Ye. M. Suleimen; syerlan75@yandex.ru

Received 24 February 2021; Revised 8 April 2021; Accepted 21 April 2021; Published 6 May 2021

Academic Editor: Wagdy Eldehna

Copyright (C) 2021 R. I. Jalmakhanbetova et al. This is an open access article distributed under the Creative Commons Attribution License, which permits unrestricted use, distribution, and reproduction in any medium, provided the original work is properly cited.

\begin{abstract}
Six amino derivatives of grossgemin (2-7) were synthesized according to the reported essential pharmacophoric features of colchicine binding site inhibitors (CBSIs). The derivatives 4-6 were obtained for the first time. The pharmacophoric features of 2-7 as CBSIs were studied to be almost identical. Furthermore, the 3D-flexible alignment of compound $\mathbf{5}$ as a representative example with colchicine showed a very good overlapping. In agreement, compounds 2-7 docked into CBS with binding modes very similar to that of colchicine and exhibited binding free energies of $-24.57,-25.05,-32.16,-29.34,-26.38$, and -26.86 (kcal/ $\mathrm{mol})$, respectively. The binding free energies of 4-7 were better than that of colchicine $(-26.13 \mathrm{kcal} / \mathrm{mol})$ with a noticeable superiority to compound 4 .
\end{abstract}

\section{Introduction}

Natural products are an untapped reservoir of biologically active compounds starting from the dawn of history and till the present $[1,2]$. The biological values of natural products are undeniable either obtained from plants $[3,4]$, marines $[5,6]$, or microbes [7-10]. The biological activities are owned to the secondary metabolites which could be classified according to their chemical structures to be saponins $[11,12]$, flavonoids $[13,14]$, pyrones [15], alkaloids [16, 17], steroids [18], and sesquiterpenes [19-21].

Grossgemin (1) is a sesquiterpene lactone of guanine structure and a characteristic component of Chartolepis intermedia Boiss. which grows in Central and Northern Kazakhstan [22]. Grossgemin (Figure 1) was previously isolated from the aerial parts of several herbal plants and exhibited a wide spectrum of biological activities [23, 24]. Various biologically active analogs of grossgemin have been synthesized before possessing cytotoxic [25-27] and antimicrobial [26] activities.

Furthermore, seven out of nine sesquiterpene lactones that have been isolated from Camchaya calcarea, having chemical structures similar to that of grossgemin, showed potent antimycobacterial and moderate antiplasmodial activity. Interestingly, three of them exhibited strong cytotoxicity against small-cell lung cancer cell lines (NCI-H187) [28].

Tubulin is the protein dimer that is the principal component of microtubule filaments. The microtubule filaments play an essential role in the mitotic nuclear division of eukaryotic cells [29]. Tubulin inhibition is one of the main targets in the field of medicinal chemistry to design and 


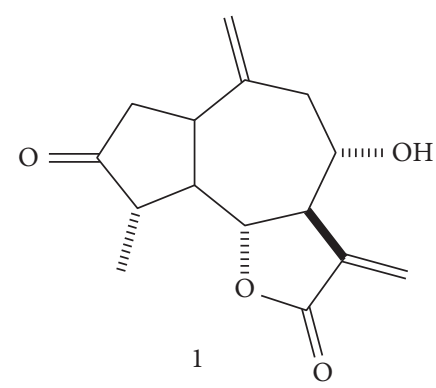

Figure 1: Chemical structure of grossgemin.

synthesize pharmacologically active drugs either as antimicrobial or anticancer drugs [30].

Colchicine binds to tubulin via the colchicine binding site that is located between the $\alpha$ and $\beta$ tubulin subunits [31]. Figure 2 explains the seven pharmacophoric features shared by all tubulin inhibitors that act as colchicine binding site inhibitors (CBSIs). These features are one hydrogen bond donor (D1), three hydrogen bond acceptors (A1, A2, and $\mathrm{A} 3)$, two hydrophobic centers ( $\mathrm{H} 1$ and $\mathrm{H} 2)$, and one planar group (R1) [32, 33]. Consequently, any molecule will have these seven pharmacophoric features or most of them will be considered as a CBSI.

It is important to mention that the pharmacophoric features of CBSIs can be presented through two planes. Features A1, D1, H1, and R1 lie in the first plane A and features $\mathrm{A} 2, \mathrm{~A} 3$, and $\mathrm{H} 2$ lie in the second plane $\mathrm{B}$. Relative to each other, planes $A$ and $B$ have a tilt of $45^{\circ}[33,34]$ (Figure 3).

\section{Results}

2.1. Synthesis of Grossgemin Analogs. To obtain new and biologically active derivatives of grossgemin, the reactions with morpholine, piperidine, and dibenzyl-, dibutyl-, diisopropyl-, and dipropylamines were undertaken under conditions similar to those described before (Figure 4) [35].

The derivatives 2,3 , and 7 were previously synthesized $[35,36]$ while derivatives $4-6$ were obtained for the first time; the structures of synthesized compounds were established using ${ }^{1} \mathrm{H},{ }^{13} \mathrm{C}$ NMR spectroscopy and two-dimensional spectroscopy DEPT, COSY, HSQC, and HMBC.

2.2. Pharmacophoric Features and Structure Alignment. Compounds 2-7 were synthesized according to the reported essential pharmacophoric features of CBSIs. Figure 5 shows that compounds $\mathbf{2}$ and $\mathbf{5}$ as examples have six out of the seven pharmacophoric features of the CBSI: hydrogen bond donor (D1), two hydrogen bond acceptors (A1 and A2), two hydrophobic centers ( $\mathrm{H} 1$ and $\mathrm{H} 2)$, and one planar group (R1).

2.3. Flexible Alignment. 3D-flexible alignment of representative compound $\mathbf{5}$ with colchicine is presented in Figure 6. In the figure, it is possible to observe that, in general, the structure of compound $\mathbf{5}$ has a very good overlap with the reference molecule (colchicine).

2.4. Molecular Docking. The synthesized compounds were docked against the colchicine binding site of tubulin heterodimers using MOE2014 software to determine the binding free energy and binding mode. The in silico molecular docking studies give a clear idea about the binding mode and the affinity between the docked candidates and the prospective protein target. The better biological effect is expected by the most similar binding mode to that of the reference ligand (colchicine) and the lower binding free energy [37].

The docking study of colchicine as a reference compound gave a binding energy value of -26.13 (Table 1). In detail, the trimethoxy phenyl ring occupied the first pocket of the colchicine binding site and could form two hydrophobic interactions with the amino acids Lys254 and Leu248. Furthermore, the side chain of the (acetamide moiety) occupied the second cavity of the colchicine binding site. The central ring formed two hydrophobic interactions with Ala250 and Leu255. Furthermore, the methoxytropone moiety occupied the third pocket of the receptor forming one hydrogen bond with Lys352 (Figure 7).

Compound 3 showed a binding mode like that of colchicine, with an affinity value of $-25.05 \mathrm{kcal} / \mathrm{mol}$ (Table 1 ). The seven-membered ring ((R)-3-methylenecycloheptan-1-ol) occupied the first cavity of the colchicine binding site forming one hydrogen bond with Lys254. The 3-(piperidin-1-ylmethyl) dihydrofuran-2 $(3 \mathrm{H})$-one moiety occupied the second cavity of the colchicine binding site, forming five hydrophobic interactions with Ala354, Cys241, Ile378, Val318, and Ala316. Additionally, it formed one hydrogen bond with Cys241. Furthermore, the 2-methylcyclopentan-1-one moiety occupied the third pocket of the colchicine binding site, forming two hydrogen bonds with Val181 and Lys352. Also, it formed three hydrophobic interactions with Ala180 and Lys352 (Figure 8).

Compound 4 as affinity value of $-32.16 \mathrm{kcal} / \mathrm{mol}$. The (1S, 6R)-6-hydroxy-1-methyl-4-methyleneoctahydroazulen-2 $(1 \mathrm{H})$-one moiety occupied the first pocket of the colchicine binding site forming three hydrogen bonds with Asn101, Asn258, and Gln11. Also, it formed a hydrophobic interaction with Ala180. The first phenyl ring and dihydrofuran-2 $(3 \mathrm{H})-$ one moiety occupied the second cavity of the colchicine binding site. The phenyl ring formed three hydrophobic interactions with Cys241, Lue255, and Ala250. The dihydrofuran-2 (3H)-one moiety formed a hydrogen bond with Ala250. The second phenyl moiety occupied the third cavity of the colchicine binding site forming two hydrophobic interactions with Lys352 and Val315 (Figure 9).

The binding mode of compound 5 was combined with a binding energy of $-29.34 \mathrm{kcal} / \mathrm{mol}$. The (1S, 6R)-6-hydroxy-1methyl-4-methyleneoctahydroazulen-2 (1H)-one moiety occupied the first cavity of the colchicine binding site, forming two hydrophobic interactions with Lys254 and Ala180. Additionally, one butyl moiety and dihydrofuran-2 $(3 \mathrm{H})$-one moiety occupied the second cavity of the 


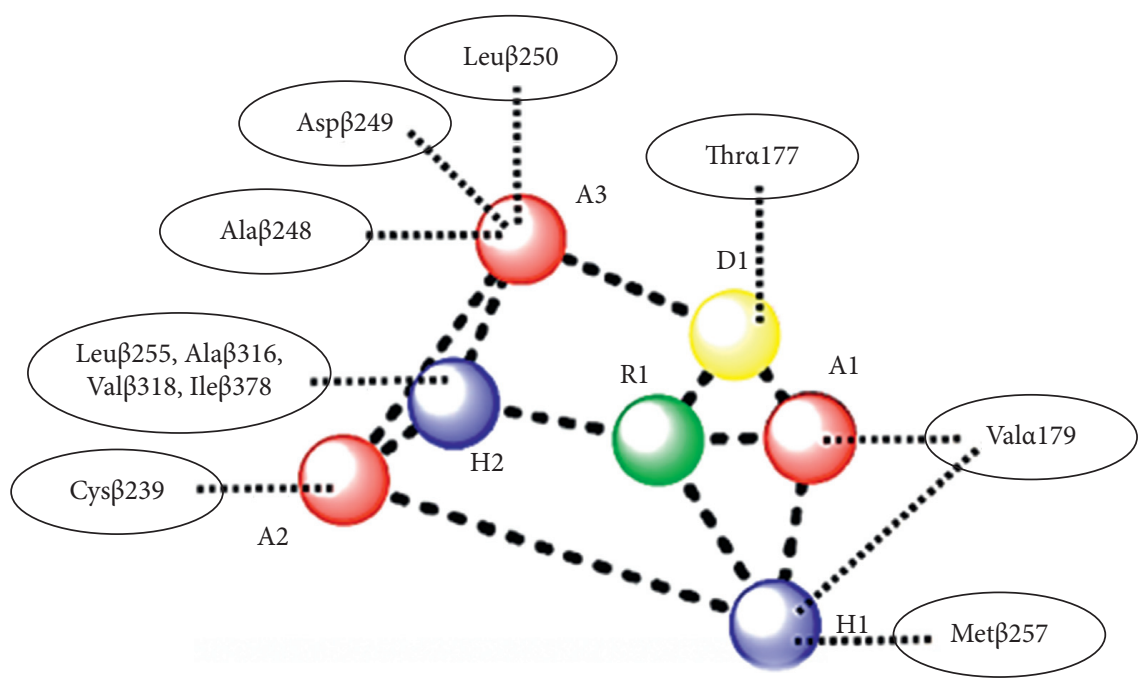

Figure 2: The seven essential pharmacophoric features of CBSIs (based on Ref. $[32,33]$ ).

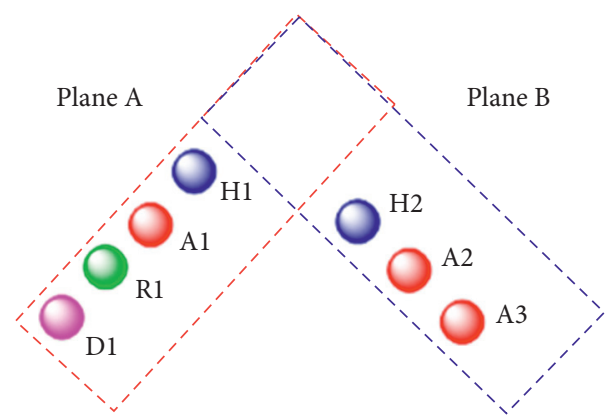

Figure 3: The pharmacophoric model of CBSIs with two planes: plane A (red) consists of points A1, D1, H1 and R1; plane B (blue) consists of points A2, A3, and H2 (based on Ref. [33, 34]).
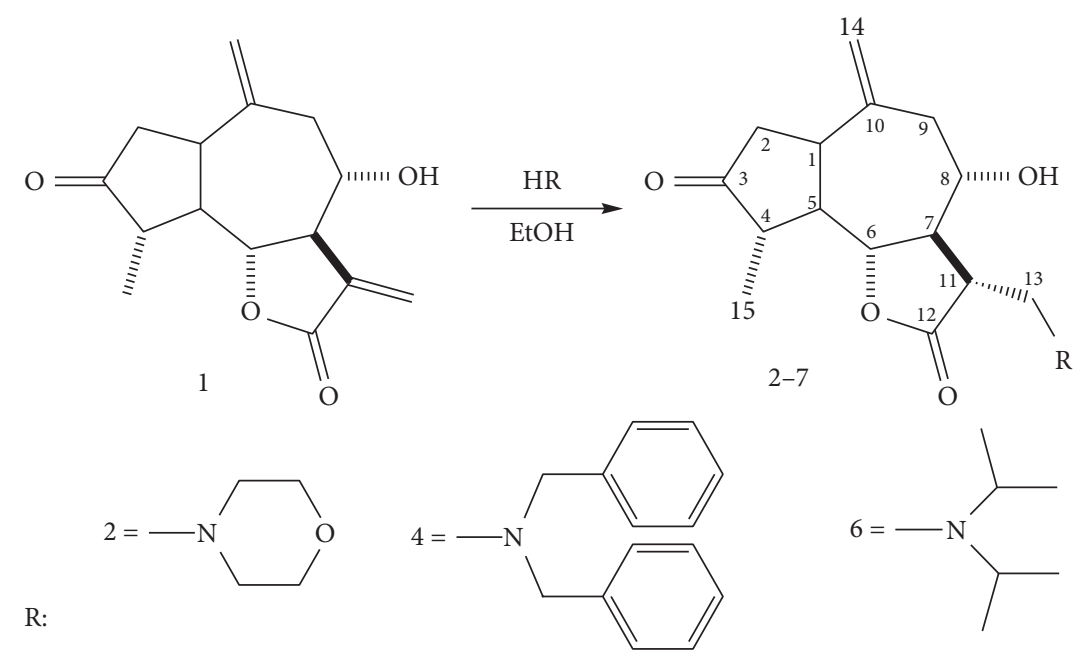

$\mathrm{R}:$
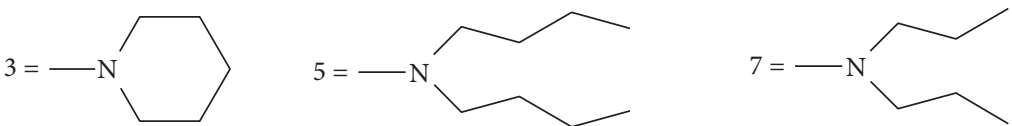

Figure 4: Scheme for the synthesis of grossgemin derivatives. 

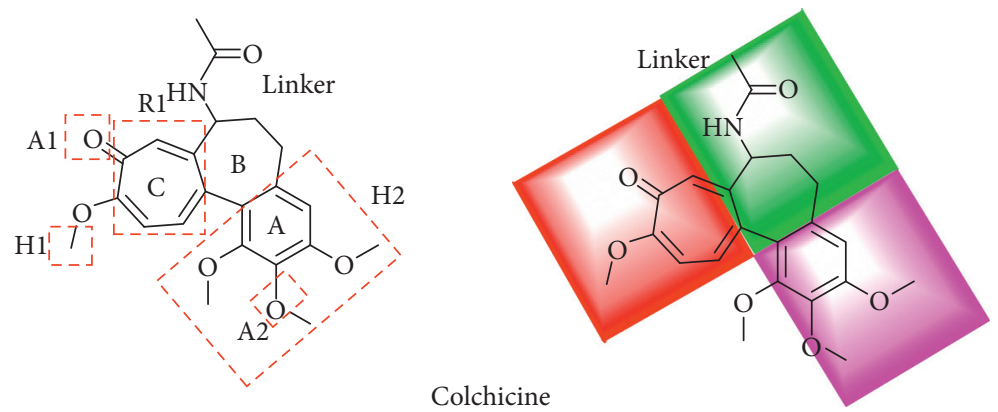

(a)

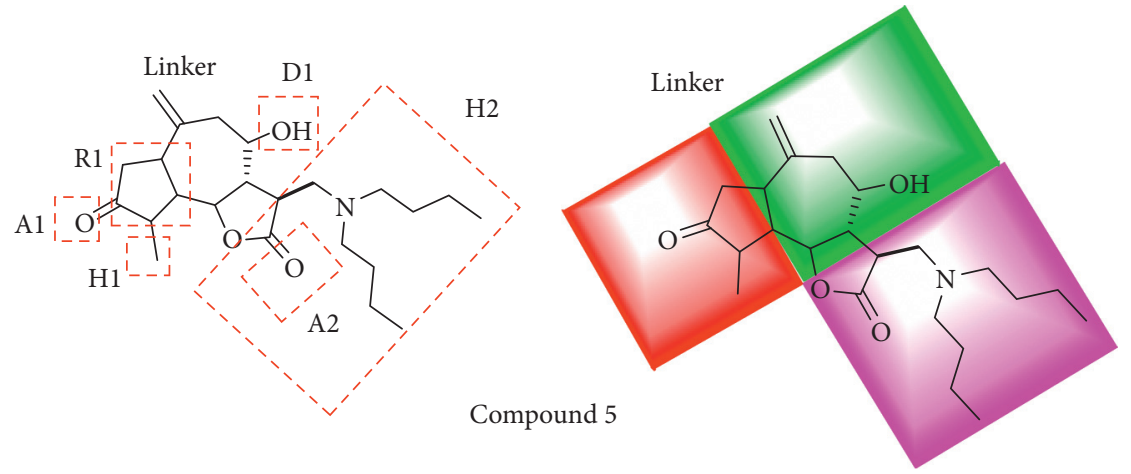

(b)
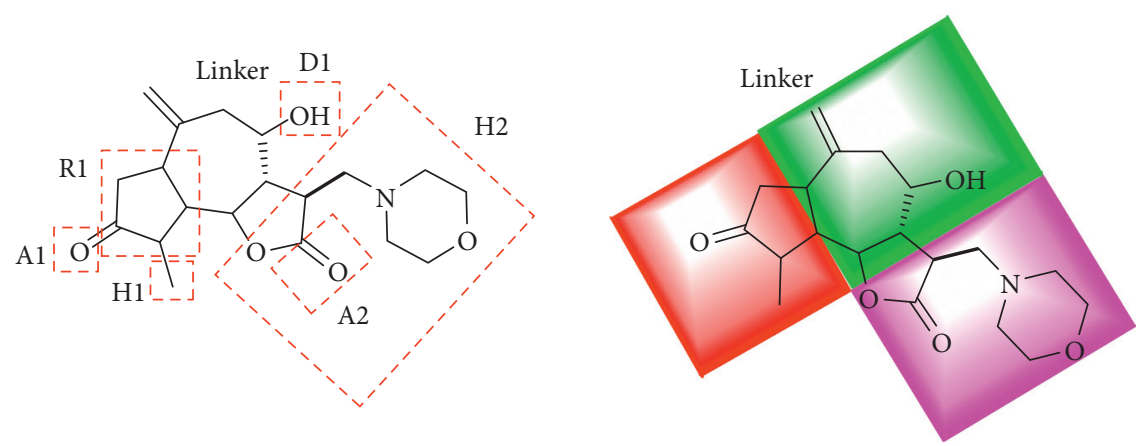

(c)

FIGURE 5: Essential pharmacophoric features of colchicine, compounds $\mathbf{2}$ and $\mathbf{5}$ as CBSIs.

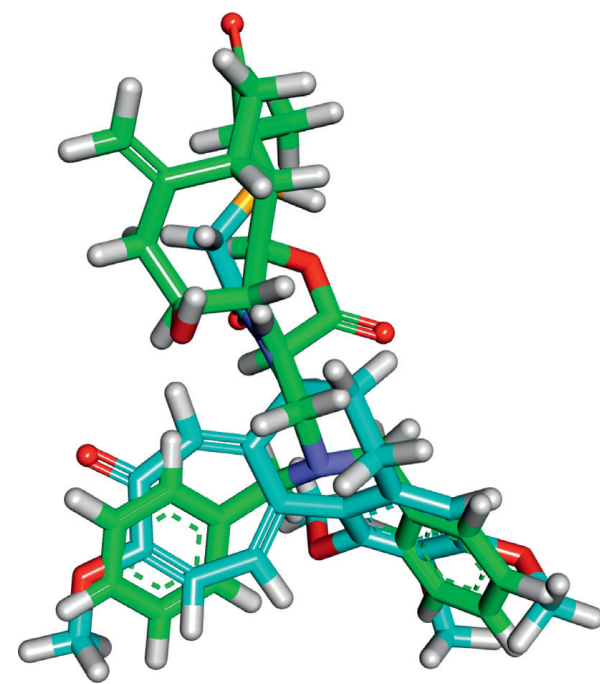

FIgURE 6: Flexible alignment of compound 5 (carbon atoms in green) with the colchicine (carbon atoms in turquoise). 
TABLE 1: The docking scores of the synthesized compounds, colchicine, and colchicine against tubulin receptor.

\begin{tabular}{lccc}
\hline Comp. & Binding free energy $(\mathrm{kcal} / \mathrm{mol})$ & Comp. & Binding free energy $(\mathrm{kcal} / \mathrm{mol})$ \\
\hline $\mathbf{1}$ & -18.00 & $\mathbf{5}$ & -29.34 \\
$\mathbf{2}$ & -24.57 & $\mathbf{6}$ & -26.38 \\
$\mathbf{3}$ & -25.05 & $\mathbf{7}$ & -26.86 \\
$\mathbf{4}$ & -32.16 & Colchicine & -26.13 \\
\hline
\end{tabular}

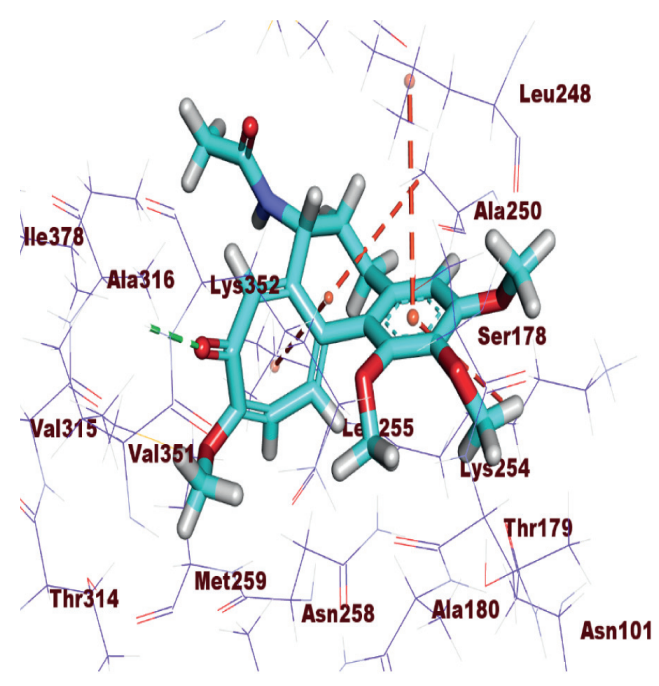

(a)

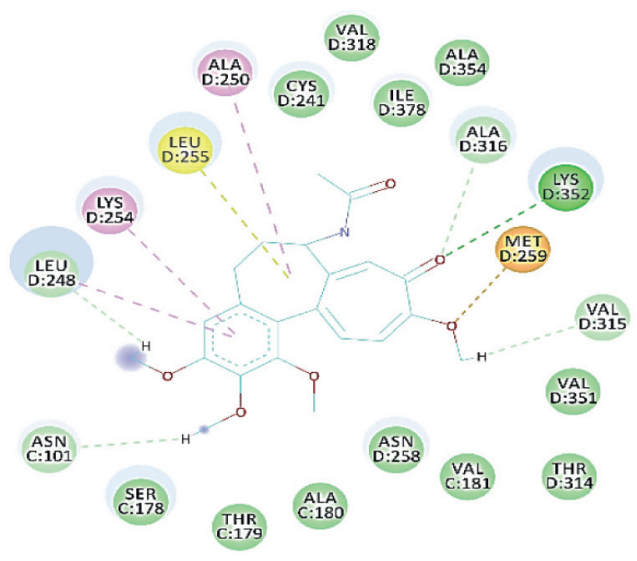

(c)

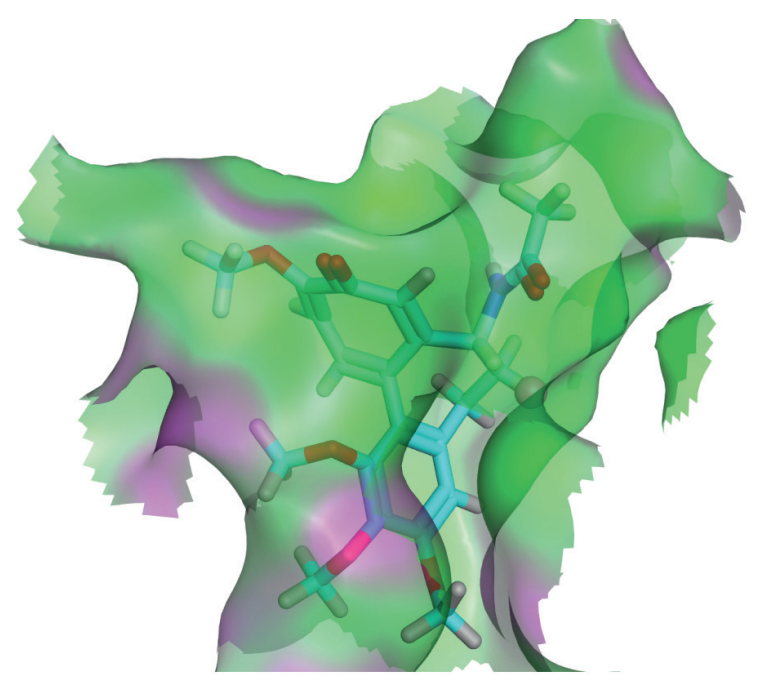

(b)

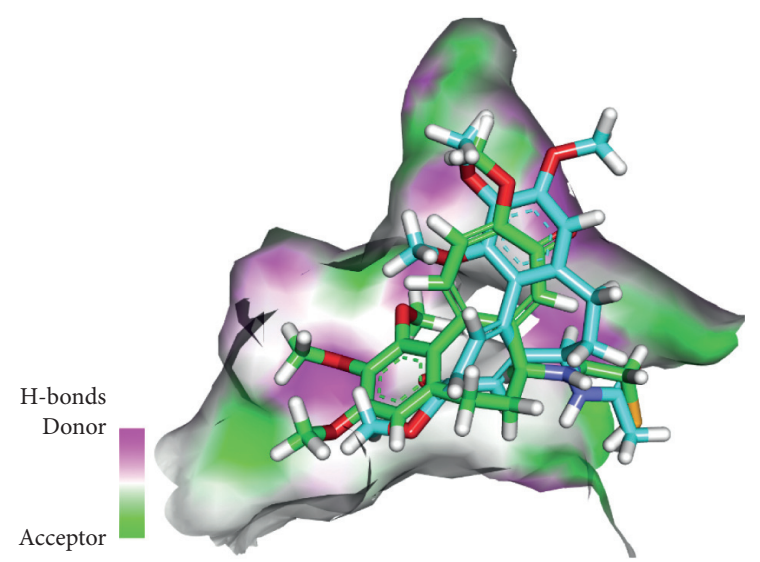

(d)

FIGURE 7: (a) 3D structure of colchicine, docked into the colchicine binding site. (b) Mapping surface showing colchicine, occupying the active pocket of colchicine binding site. (c) 2D structure of colchicine, docked into the colchicine binding site. (d) 3D alignment of colchicine (carbon atoms in turquoise) with the DAMA-colchicine (carbon atoms in green).

colchicine binding site, forming two hydrophobic interactions with Cys241 and Ala316. Also, it formed a hydrogen bond with Leu255. Furthermore, the other butyl moiety occupied the third pocket of the colchicine binding site forming two hydrophobic interactions with Val181 and Met259 (Figure 10).

\section{Experimental}

3.1. General Procedure for the Preparation of Amino Derivatives of Grossgemin 2-7. A sample of grossgemin 1 was dissolved with $3 \mathrm{ml}$ of ethyl alcohol at $20^{\circ} \mathrm{C}$ and the amine was added in a ratio of $1: 1.2$ to 1 with intensive stirring. After the end of the reaction (15-60 min, TLC control in the hexaneethyl acetate system $(1: 1.5)$, manifestation, by spraying $1 \%$ vanillin solution in $\mathrm{H}_{2} \mathrm{SO}_{4}$ and a saturated solution of $\mathrm{KMnO}_{4}$ ), the mixture was washed $1: 1$ with the $\mathrm{CHCl}_{3}: \mathrm{H}_{2} \mathrm{O}(\mathrm{x} 3)$ system and the organic part was separated in a dividing funnel. The resulting solution was dried with $\mathrm{Na}_{2} \mathrm{SO}_{4}$ and filtered and then distilled on a rotary evaporator. Purification was carried out by CC, depending on the purity of the product. The yield of derivatives $2-7$ is from 37.74 to $90.53 \%$. 


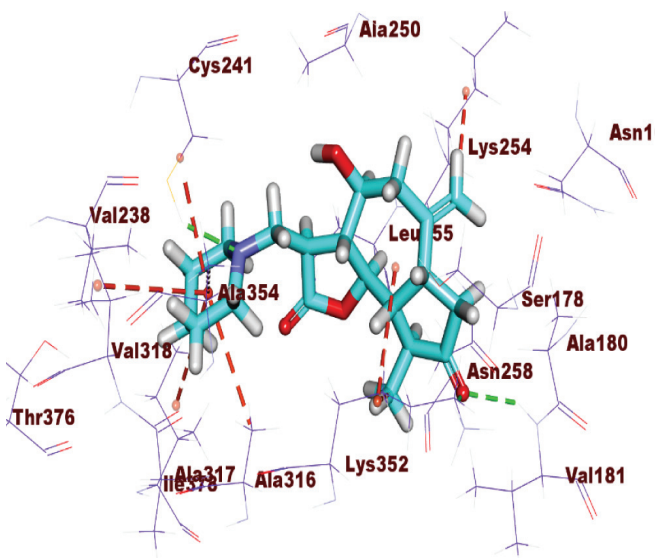

(a)

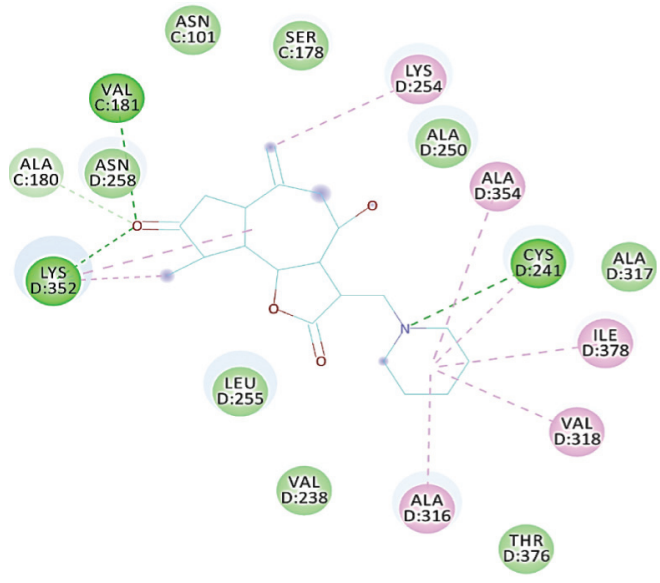

(c)

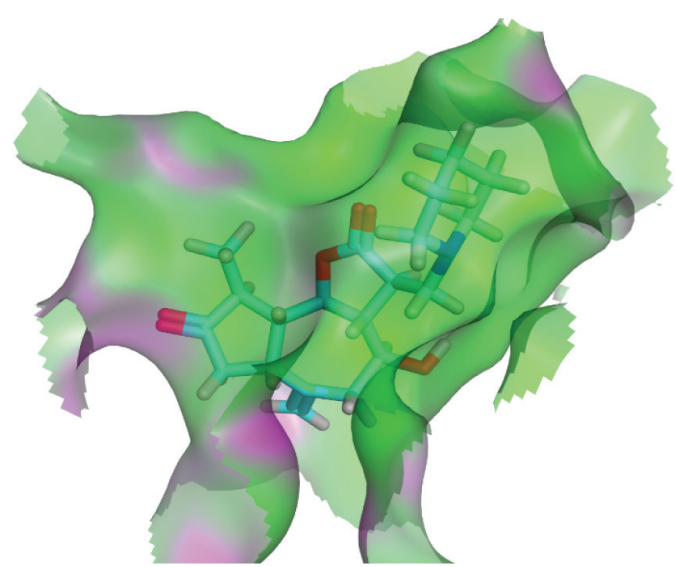

(b)

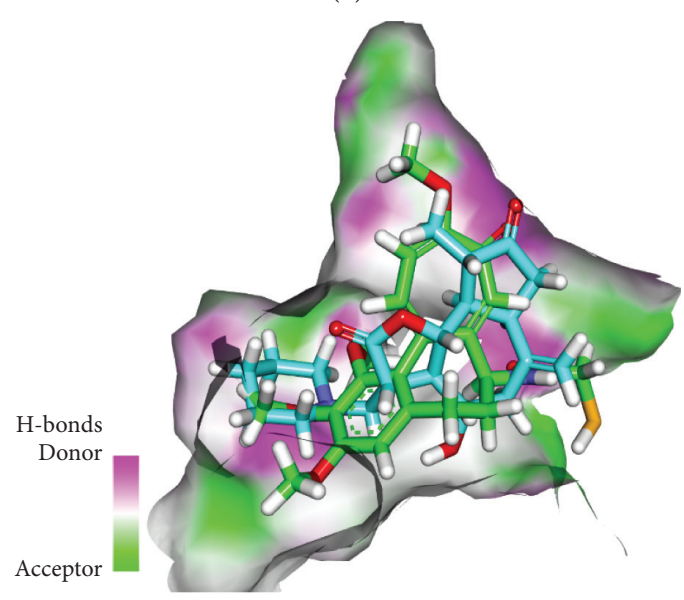

(d)

FIGURE 8: (a) 3D structure of compound 3, docked into the colchicine binding site. (b) Mapping surface showing compound 3, occupying the active pocket of colchicine binding site. (c) $2 \mathrm{D}$ structure of compound 3 , docked into the colchicine binding site. (d) $3 \mathrm{D}$ alignment of compound 3 (carbon atoms in turquoise) with the DAMA-colchicine (carbon atoms in green).

3.1.1. 13-Dibenzylamino-3-keto-1,5,7 $\alpha, 4,6,8 \beta(H)-8(\alpha)$-hydroxyguai-10(14)-en-12,6-olide 4. A colorless oily substance with the composition of $\mathrm{C}_{29} \mathrm{H}_{32} \mathrm{NO}_{4}$. $\mathrm{R} 0.71$. Yield $49 \mathrm{mg}$ $(90.53 \%)$.

$\mathrm{NMR}{ }^{1} \mathrm{H}\left(500 \mathrm{MHz}, \mathrm{CDCl}_{3}, \delta, \mathrm{ppm}, \mathrm{J} / \mathrm{Hz}\right): 2.20(1 \mathrm{H}, \mathrm{m}$, $\mathrm{H}-1), 2.07$ (1) m, H-2a $), 2.88$ (1H, m, H-2b), 1.81 (1H, q, $J=9.8, \mathrm{H}-4), 2.02$ (1H, m, H-5), $3.83(1 \mathrm{H}, \mathrm{m}, \mathrm{H}-6), 2.53(1 \mathrm{H}$, t, $J=9, \mathrm{H}-7), 3.49(1 \mathrm{H}, \mathrm{td}, J=5.7 ; 9.5, \mathrm{H}-8), 2.45(2 \mathrm{H}, \mathrm{d}$, $J=6.9, \mathrm{H}-9), 2.88$ (1H, d, H-11), $2.70(1 \mathrm{H}, \mathrm{t}, J=13.3, \mathrm{H}-13 \mathrm{a})$, $3.04(1 \mathrm{H}, \mathrm{dd}, J=2.3 ; 13.5, \mathrm{H}-13 \mathrm{~b}), 4.69,5.03$ (each $1 \mathrm{H}, \mathrm{s}$, $\mathrm{H}-14 \mathrm{a}, 14 \mathrm{~b}), 1.15$ (3H, d, J=7.1, H-15), 3.43 (2H at C-16, 17, $\mathrm{d}, J=12.9, \mathrm{H}-16 \mathrm{a}, 17 \mathrm{a}), 3.89(2 \mathrm{H}$ at $\mathrm{C}-16,17, \mathrm{~d}, J=12.9$, H-16b, 17b), 7.35 (10H at C-20-29, m, H-20-29).

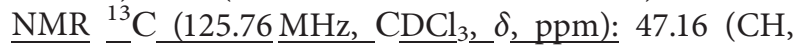
$\mathrm{C}-1), 47.70(\mathrm{CH}, \mathrm{C}-2), 175.08$ (C, C-3), 54.98 (CH, C-4), 51.06 (CH, C-5), 83.05 (CH, C-6), 44.76 (CH, C-7), 73.76 (CH, C-8), $43.33\left(\mathrm{CH}_{2}, \mathrm{C}-9\right), 52.79(\mathrm{C}, \mathrm{C}-10), 39.53(\mathrm{CH}$, C-11), 144.32 (C, C-12), $55.44\left(\mathrm{CH}_{2}, \mathrm{C}-13\right), 114.39\left(\mathrm{CH}_{2}\right.$, C-14), $14.47\left(\mathrm{CH}_{3}, \mathrm{C}-15\right), 59.61\left(\mathrm{CH}_{2}, \mathrm{C}-16\right), 59.61\left(\mathrm{CH}_{2}\right.$, C-17), 136.10 (C, C-18), 136.10 (C, C-19), 130.13 (CH, C-20), 130.13 (CH, C-21), 128.68 (CH, C-22), 128.68 (CH, C-23),
127.97 (CH, C-24), 127.97 (CH, C-25), 128.68 (CH, C-26), 128.68 (CH, C-27), 130.13 (CH, C-28), 130.13 (CH, C-29).

3.1.2. 13-Dibutylamino-3-keto-1,5,7 $\alpha, 4,6,8 \beta(H)-8(\alpha)$-hydroxyguai-10(14)-en-12,6-olide 5. A colorless oily substance with the composition of $\mathrm{C}_{23} \mathrm{H}_{36} \mathrm{NO}_{4}$. $\mathrm{R}_{f} 0.66$. Yield $28 \mathrm{mg}$ (37.74\%).

NMR ${ }^{1} \mathrm{H}\left(500 \underline{\mathrm{MHz},} \mathrm{CDCl}_{3}, \delta, \mathrm{ppm}, \mathrm{J} / \mathrm{Hz}\right): 3.11(1 \mathrm{H}, \mathrm{td}$, $J=5.1 ; 7.9, \mathrm{H}-1), 2.50(2 \mathrm{H}, \overline{\mathrm{t}, J}=7.8, \mathrm{H}-2), 2.31(1 \mathrm{H}, \mathrm{m}, \mathrm{H}-4)$, $2.66(1 \mathrm{H}, \mathrm{m}, \mathrm{H}-5), 4.01(1 \mathrm{H}, \mathrm{t}, J=9.5, \mathrm{H}-6), 2.25(1 \mathrm{H}, \mathrm{m}$, H-7), 3.58 (1H, td, $J=5.7 ; 9.4, \mathrm{H}-8), 1.23$ (2H, d, $J=7, \mathrm{H}-9)$, 2.25 (1H, m, H-11), 2.58 (1H, m, H-13a), 3.04 (1H, dd, $J=9.5$; 13.2, H-13b), 4.74, 5.05 (each 1H, s, H-14a, 14b), 1.21 (3H, d, $J=7, \mathrm{H}-15), 2.87(2 \mathrm{H}$ at $\mathrm{C}-16,17, \mathrm{dd}, J=5.5 ; 12.8, \mathrm{H}-16 \mathrm{a}$, 17a), 2.15 (2H at C-16, 17, t, J=9.6, H-16b, 17b), 1.47 (4H at $\mathrm{C}-18,19, \mathrm{~m}, \mathrm{H}-18-19), 1.29$ (4H at C-20, 21, sq, $J=7.2$, $\mathrm{H}-20-21), 0.91$ (4H at C-22, 23, t, $J=7.3, \mathrm{H}-22-23)$.

$\mathrm{NMR}{ }^{13} \mathrm{C}\left(125.76 \mathrm{MHz}, \mathrm{CDCl}_{3}, \delta, \mathrm{ppm}\right): 39.76(\mathrm{CH}$, C-1), $43.22(\mathrm{CH}, \mathrm{C}-2), 175.28$ (C, C-3), 47.24 (CH, C-4), 45.77 (CH, C-5), 82.74 (CH, C-6), 51.03 (CH, C-7), 73.68 


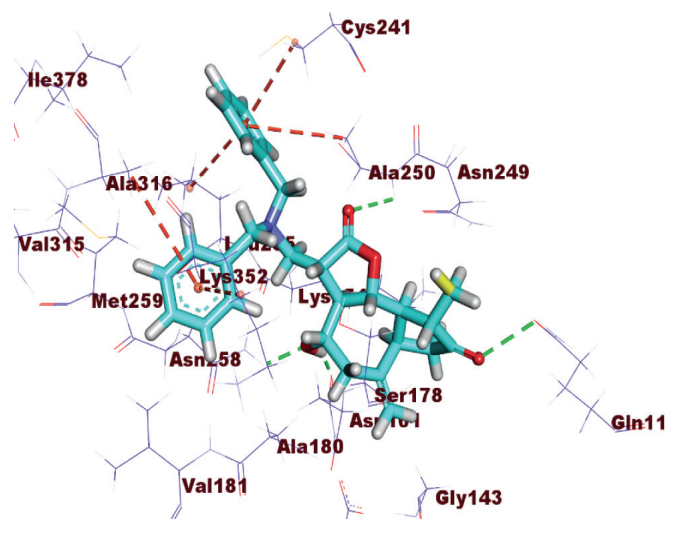

(a)

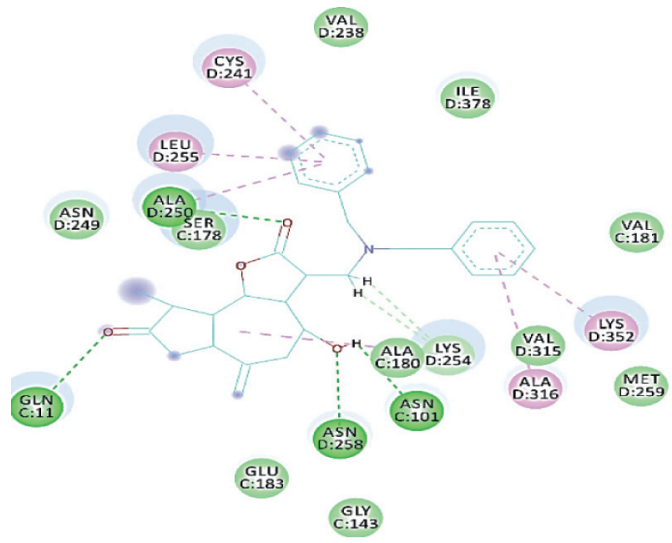

(c)

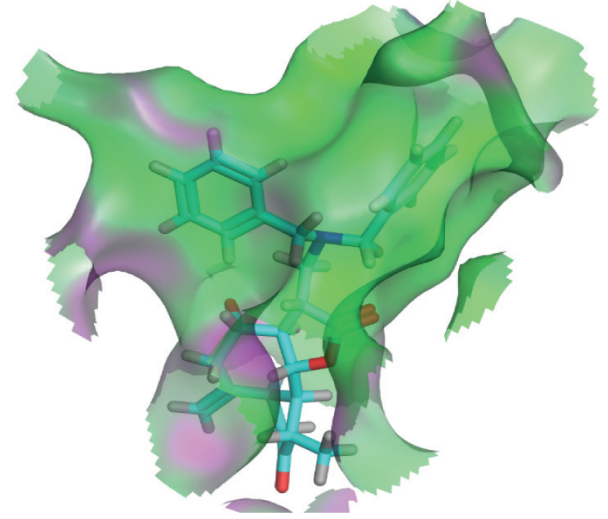

(b)

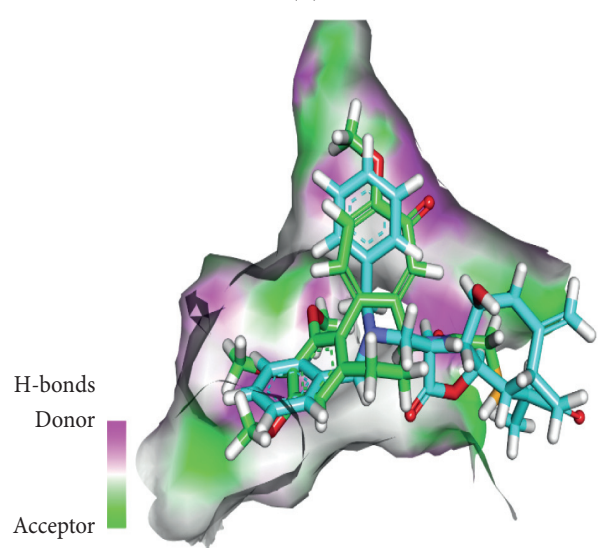

(d)

Figure 9: (a) 3D structure of compound 4, docked into the colchicine binding site. (b) Mapping surface showing compound 4, occupying the active pocket of colchicine binding site. (c) $2 \mathrm{D}$ structure of compound 4 , docked into the colchicine binding site. (d) 3D alignment of compound 4 (carbon atoms in turquoise) with the DAMA-colchicine (carbon atoms in green).

(CH, C-8), $29.69\left(\mathrm{CH}_{2}, \mathrm{C}-9\right), 53.60$ (C, C-10), $56.34(\mathrm{CH}$, C-11), 144.38 (C, C-12), $55.87\left(\mathrm{CH}_{2}, \mathrm{C}-13\right), 114.42\left(\mathrm{CH}_{2}\right.$, C-14), $14.73\left(\mathrm{CH}_{3}, \mathrm{C}-15\right), 47.53\left(\mathrm{CH}_{2}, \mathrm{C}-16\right), 47.53\left(\mathrm{CH}_{2}\right.$, C-17), $27.94\left(\mathrm{CH}_{2}, \mathrm{C}-18\right), 27.94\left(\mathrm{CH}_{2}, \mathrm{C}-19\right), 20.69\left(\mathrm{CH}_{2}\right.$, C-20), $20.69\left(\mathrm{CH}_{2}, \mathrm{C}-21\right), 13.93\left(\mathrm{CH}_{3}, \mathrm{C}-22\right), 13.93\left(\mathrm{CH}_{3}\right.$, C-23).

3.1.3. 13-Di-isopropylamino-3-keto-1,5,7 $\alpha, 4,6,8 \beta(H)-8(\alpha)$ hydroxy-guai-10(14)-en-12,6-olide 6. A colorless crystalline substance with the composition of $\mathrm{C}_{21} \mathrm{H}_{32} \mathrm{NO}_{4}$. $\mathrm{R}_{f} 0.53$. Yield $47.8 \mathrm{mg}$ (69.3\%). M.p. $93.0-93.6^{\circ} \mathrm{C}$.

NMR ${ }^{1} \mathrm{H}\left(500 \mathrm{MHz}, \mathrm{CDCl}_{3}, \delta, \mathrm{ppm}, \mathrm{J} / \mathrm{Hz}\right): 3.12(1 \mathrm{H}, \mathrm{td}$,

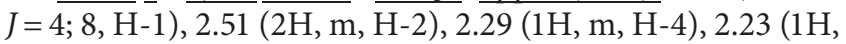
$\mathrm{m}, \mathrm{H}-5), 4.00(1 \mathrm{H}, \mathrm{m}, \mathrm{H}-6), 2.47(1 \mathrm{H}, \mathrm{m}, \mathrm{H}-7), 2.81(1 \mathrm{H}, \mathrm{m}$, $\mathrm{H}-8), 3.51(1 \mathrm{H}, \mathrm{t}, J=9.1, \mathrm{H}-9 \mathrm{a}), 4.00(1 \mathrm{H}, \mathrm{m}, \mathrm{H}-9 \mathrm{~b}), 3.65(1 \mathrm{H}$, $\mathrm{td}, J=5.8 ; 9.5, \mathrm{H}-11), 2.20$ and $2.84(2 \mathrm{H}, \mathrm{m}, \mathrm{H}-13), 4.76,5.06$ (each $1 \mathrm{H}, \mathrm{s}, \mathrm{H}-14 \mathrm{a}, 14 \mathrm{~b}), 1.21(3 \mathrm{H}, \mathrm{d}, J=6.8, \mathrm{H}-15), 3.44(2 \mathrm{H}$ at $\mathrm{C}-16,17, \mathrm{~s}, \mathrm{H}-16,17), 1.23(12 \mathrm{H}$ at $\mathrm{C}-18-21, \mathrm{~d}, J=8.1$, H-18-21).

NMR [13]C (125.76 MHz, $\left.\mathrm{CDCl}_{3}, \delta, \mathrm{ppm}\right): 39.78(\mathrm{CH}$, $\mathrm { C } - 1 \longdiv { ) , 4 3 . 2 5 } ( \mathrm { CH } , \mathrm { C } - 2 ), \overline{174.03}(\overline{\mathrm{C}, \mathrm{C}-3), 47.21}(\mathrm{CH}, \mathrm{C}-4)$, 51.13 (CH, C-5), 82.93 (CH, C-6), 53.49 (CH, C-7), 47.48 (CH, C-8), $71.93\left(\mathrm{CH}_{2}, \mathrm{C}-9\right), 29.68$ (C, C-10), $74.14(\mathrm{CH}$, C-11), 143.90 (C, C-12), $47.04\left(\mathrm{CH}_{2}, \mathrm{C}-13\right), 114.90\left(\mathrm{CH}_{2}\right.$,
C-14), $14.65\left(\mathrm{CH}_{3}, \mathrm{C}-15\right), 59.27(\mathrm{CH}, \mathrm{C}-16), 59.27(\mathrm{CH}$, C-17), $14.65\left(\mathrm{CH}_{3}, \mathrm{C}-18\right), 14.65\left(\mathrm{CH}_{3}, \mathrm{C}-19\right), 14.65\left(\mathrm{CH}_{3}\right.$, C-20), $14.65\left(\mathrm{CH}_{3}, \mathrm{C}-21\right)$.

3.2. Docking. Crystallographic structure of tubulin [PDB ID: 1SA0, resolution $3.00 \AA$ ] was retrieved from Protein Data Bank (http://www.pdb.org) and considered as a target for docking simulation. The docking analysis was performed using MOE2014 software to evaluate the free energy and binding modes of the synthesized compounds against tubulin. At first, the crystal structure of the target was prepared by removing water molecules and retaining the two essential chains and the cocrystallized ligand, $\mathrm{N}$-deacetyl- $\mathrm{N}$ (2-mercaptoacetyl)-colchicine (DAMA-colchicine). Then, the protein structure was protonated, and the hydrogen atoms were hidden. Next, the energy was minimized, and the binding pocket of the protein was defined [34].

The $2 \mathrm{D}$ structures of the synthesized compounds and reference ligand (colchicine) were sketched using ChemBioDraw Ultra 14.0 and saved as MDL-SD format. Then, the saved files were opened using MOE and 3D structures were protonated. Next, energy minimization was applied. Before the docking process, validation of the docking protocol was carried out by running the 


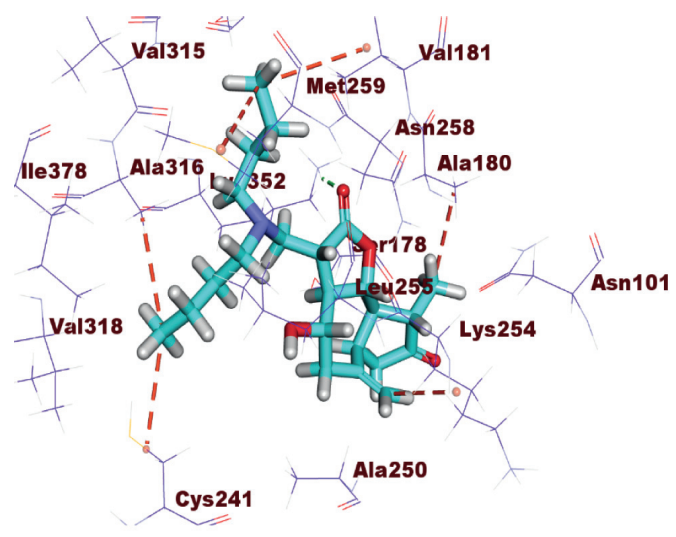

(a)

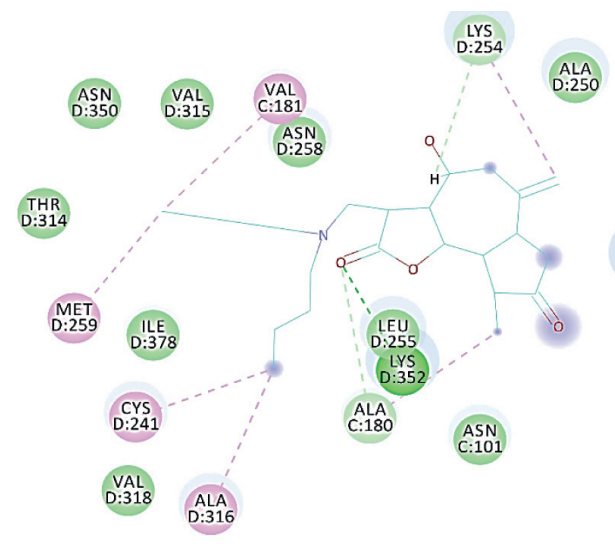

(c)

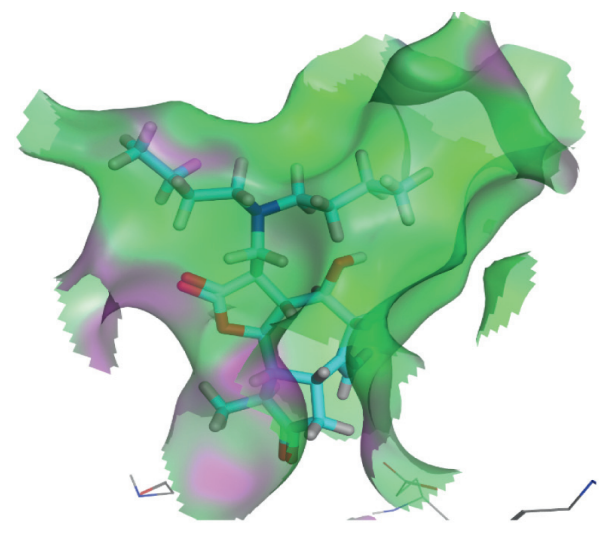

(b)

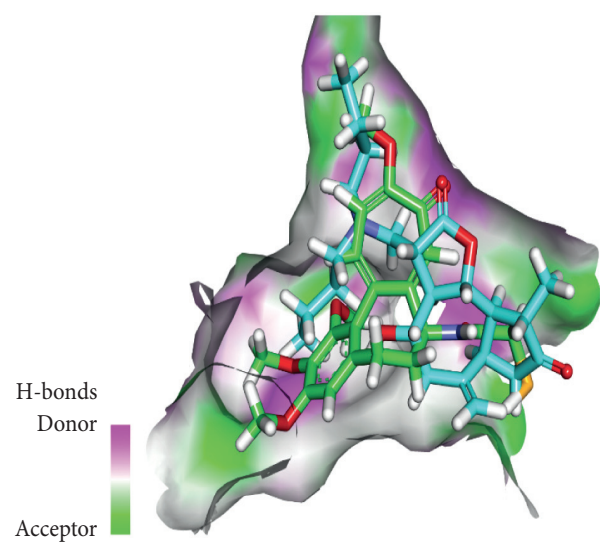

(d)

FIGURE 10: (a) 3D structure of compound 5, docked into the colchicine binding site. (b) Mapping surface showing compound 5, occupying the active pocket of colchicine binding site. (c) 2D structure of compound 5, docked into the colchicine binding site. (d) 3D alignment of compound 5 (carbon atoms in turquoise) with the DAMA-colchicine (carbon atoms in green).

simulation only using the cocrystallized ligand (DAMAcolchicine) which showed a low RMSD value. The molecular docking of the synthesized was performed using a default protocol against the target receptor. In each case, 30 docked structures were generated using genetic algorithm searches; ASE was used for scoring and force field (MMFF94) for refinement [38, 39].

\section{Conclusion}

Six grossgemin amino derivatives (2-7) were synthesized according to be colchicine binding site inhibitors (CBSIs). Six (out of seven) pharmacophoric features as CBSIs were achieved in 2-7. Furthermore, the 3D-flexible alignment of compound $\mathbf{5}$ as a representative example with colchicine showed a very good overlapping. Consequently, compounds 2-7 were docked into CBS with binding modes very similar to that of colchicine and exhibited very good binding free energies that were better than that of colchicine in compounds 4-7 with a noticeable superiority to compound 4 . The obtained compounds (2-7), especially compound 4, could be promising antimicrobial and/or anticancer candidates through being CBSIs.

\section{Data Availability}

NMR data of compounds 2-7 are available from the corresponding author.

\section{Conflicts of Interest}

The authors declare that they have no conflicts of interest.

\section{Acknowledgments}

The authors thank doctor G. G. Sissengaliyeva for help in the synthesis of compounds.

\section{References}

[1] S. Nobili, D. Lippi, E. Witort et al., "Natural compounds for cancer treatment and prevention," Pharmacological Research, vol. 59, no. 6, pp. 365-378, 2009.

[2] R. Gyawali and S. A. Ibrahim, "Natural products as antimicrobial agents," Food Control, vol. 46, pp. 412-429, 2014.

[3] A. M. Metwaly, Z. Lianlian, H. Luqi, and D. Deqiang, "Black ginseng and its saponins: preparation, phytochemistry and pharmacological effects," Molecules, vol. 24, no. 10, p. 1856, 2019. 
[4] Y.-M. Wang, X.-K. Ran, M. Riaz et al., "Chemical constituents of stems and leaves of tagetespatula L. And its fingerprint," Molecules, vol. 24, no. 21, p. 3911, 2019.

[5] S. V. Sperstad, T. Haug, H.-M. Blencke, O. B. Styrvold, C. Li, and K. Stensvåg, "Antimicrobial peptides from marine invertebrates: challenges and perspectives in marine antimicrobial peptide discovery," Biotechnology Advances, vol. 29, no. 5, pp. 519-530, 2011.

[6] A. El-Demerdash, A. M. Metwaly, A. El-Aziz, T. Mohamed, I. H. Eissa, and J. D. Stockand, 2020.

[7] A. M. Metwaly, A. S. Wanas, M. M. Radwan, S. A. Ross, and M. A. ElSohly, "New $\alpha$-Pyrone derivatives from the endophytic fungus Embellisia sp," Medicinal Chemistry Research, vol. 26, no. 8, pp. 1796-1800, 2017.

[8] A. Metwaly, H. Kadry, A. El-Hela, A. Elsalam, and S. Ross, "New antimalarial benzopyran derivatives from the endophytic fungus Alternaria phragmospora," Planta Medica, vol. 80, no. 10, p. PC11, 2014.

[9] A. Metwaly, "Comparative biological evaluation of four endophytic fungi isolated from nigella sativa seeds," Al-Azhar Journal of Pharmaceutical Sciences, vol. 59, no. 1, pp. 123-136, 2019.

[10] D. Balpanov, G. Sissengaliyeva, R. Khannanov, and T. Seilkhanov, ХАБАРШЫСЫ, vol. 1, p. 35, 2020.

[11] M. H. Sharaf, G. M. El-Sherbiny, S. A. Moghannem et al., Scientific Reports, vol. 11, pp. 1-16, 2021.

[12] A. M. Yassin, N. M. El-Deeb, A. M. Metwaly, G. F. El Fawal, M. M. Radwan, and E. E. Hafez, "Induction of apoptosis in human cancer cells through extrinsic and intrinsic pathways by balanites aegyptiaca furostanol saponins and saponincoated SilverNanoparticles," Applied Biochemistry and Biotechnology, vol. 182, no. 4, pp. 1675-1693, 2017.

[13] L. Liu, S. Luo, M. Yu et al., "Chemical constituents ofTagetes patulaand their neuroprotecting action," Natural Product Communications, vol. 15, no. 11, Article ID 1934578X2097450, 2020.

[14] M. M. Ghoneim, W. M. Afifi, M. Ibrahim et al., "Biological evaluation and molecular docking study of metabolites from Salvadora Persica L. Growing in Egypt," Pharmacognosy Magazine, vol. 15, p. 232, 2019.

[15] A. M. Metwaly, F. R. Fronczek, G. Ma et al., "Antileukemic $\alpha$-pyrone derivatives from the endophytic fungus Alternaria phragmospora," Tetrahedron Letters, vol. 55, no. 24, pp. 3478-3481, 2014.

[16] Metwaly, M. Ahmed, M. G. Mohammed, and A. Musa, "Two new antileishmanial diketopiperazine alkaloids from the endophytic fungus Trichosporum sp.," Derpharmachemica, vol. 7, pp. 322-327, 2015.

[17] A. El-Demerdash, A. M. Metwaly, A. Hassan et al., "Comprehensive virtual screening of the antiviral potentialities of marine polycyclic guanidine alkaloids against SARS-CoV-2 (COVID-19)," Biomolecules, vol. 11, no. 3, p. 460, 2021.

[18] A. M. Metwaly, H. A. Kadry, A. A. El-Hela et al., "Nigrosphaerin A a new isochromene derivative from the endophytic fungus Nigrospora sphaerica," Phytochemistry Letters, vol. 7, pp. 1-5, 2014.

[19] J. Y. Cho, A. R. Kim, H.-G. Joo et al., "Cynaropicrin, a sesquiterpene lactone, as a new strong regulator of CD29 and CD98 functions," Biochemical and Biophysical Research Communications, vol. 313, no. 4, pp. 954-961, 2004.

[20] J. Y. Cho, K. U. Baik, J. H. Jung, and M. H. Park, "In vitro antiinflammatory effects of cynaropicrin, a sesquiterpene lactone, from Saussurea lappa," European Journal of Pharmacology, vol. 398, no. 3, pp. 399-407, 2000.
[21] M. F. Elsebai, A. Mocan, and A. G. Atanasov, "Cynaropicrin: a comprehensive research review and therapeutic potential as an anti-hepatitis c virus agent," Frontiers in Pharmacology, vol. 7, p. 472, 2016.

[22] N. V. Pavlov, Flora of Kazakhstan (in Russian), vol. 9, p. 127, 1966.

[23] M. N. Mukhametzhanov, V. I. Sheichenko, K. S. Rybalko, and K. I. Boryaev, "Isolation of grosshemin fromChartolepis intermedia," Chemistry of Natural Compounds, vol. 5, no. 3, pp. 158-160, 1969.

[24] M. Bruno, S. Bancheva, S. Rosselli, and A. Maggio, "Sesquiterpenoids in subtribe centaureinae (cass.) dumort (tribe cardueae, asteraceae): distribution, 13C NMR spectral data and biological properties," Phytochemistry, vol. 95, pp. 19-93, 2013.

[25] P. Barbetti, G. Fardella, I. Chiappini, V. Scarcia, and A. Furlani Candiani, "New cytotoxic selenoderivatives of guaianolides," European Journal of Medicinal Chemistry, vol. 24, no. 3, pp. 299-305, 1989.

[26] A. T. Kulyyasov, S. M. Adekenov, T. S. Seitembetov, and K. D. Rakhimov, "Chemical modification of grosshemin in the lactone ring," Chemistry of Natural Compounds, vol. 31, no. 2, pp. 192-195, 1995.

[27] P. Barbetti, G. Fardella, I. Chiappini, V. Scarcia, and A. F. Candiani, "Il farmaco," Edizione Scientifica, vol. 40, pp. 755-769, 1985.

[28] N. Vongvanich, P. Kittakoop, P. Charoenchai, S. Intamas, K. Sriklung, and Y. Thebtaranonth, "Antiplasmodial, antimycobacterial, and cytotoxic principles from Camchaya calcarea," Planta Medica, vol. 72, no. 15, pp. 1427-1430, 2006.

[29] D. H. Young, "Anti-tubulin agents," in Fungicide Resistance in Plant Pathogens, pp. 93-103, Springer, Berlin, Germany, 2015.

[30] T. Kiso, K.-I. Fujita, X. Ping, T. Tanaka, and M. Taniguchi, "Screening for microtubule-disrupting antifungal agents by using a mitotic-arrest mutant of Aspergillus nidulans and novel action of phenylalanine derivatives accompanying tubulin loss," Antimicrobial Agents and Chemotherapy, vol. 48, no. 5, pp. 1739-1748, 2004.

[31] A. Tripathi, D. Durrant, R. M. Lee et al., "Hydropathic analysis and biological evaluation of stilbene derivatives as colchicine site microtubule inhibitors with anti-leukemic activity," Journal of Enzyme Inhibition and Medicinal Chemistry, vol. 24, no. 6, pp. 1237-1244, 2009.

[32] Y. Lu, J. Chen, M. Xiao, W. Li, and D. D. Miller, “An overview of tubulin inhibitors that interact with the colchicine binding site," Pharmaceutical Research, vol. 29, no. 11, pp. 2943-2971, 2012.

[33] T. L. Nguyen, C. McGrath, A. R. Hermone et al., "A common pharmacophore for a diverse set of colchicine site inhibitors using a structure-based approach," Journal of Medicinal Chemistry, vol. 48, no. 19, pp. 6107-6116, 2005.

[34] A. M. El-Naggar, I. H. Eissa, A. Belal, and A. A. El-Sayed, "Design, eco-friendly synthesis, molecular modeling and anticancer evaluation of thiazol-5 $(4 \mathrm{H})$-ones as potential tubulin polymerization inhibitors targeting the colchicine binding site," RSC Advances, vol. 10, no. 5, pp. 2791-2811, 2020.

[35] S. M. Adekenov, "Sesquiterpene plant lactones of Kazakhstan," Structure properties and applications, p. 385, Chemical Science, Moscow, 1992.

[36] E. Najdenova, Presented in Part at the the Materials of Scientific Conference, in Proceedings of the International Conference of Chemical Engineering \& Industrial Biotechnology, Sofia, Bulgaria, November 1981. 
[37] A. G. A. El-Helby, R. R. Ayyad, H. M. Sakr et al., "Design, synthesis, molecular modeling and biological evaluation of novel 2,3-dihydrophthalazine-1,4-dione derivatives as potential anticonvulsant agents," Journal of Molecular Structure, vol. 1130, pp. 333-351, 2017.

[38] A. A. Nasser, I. H. Eissa, M. R. Oun et al., "Discovery of new pyrimidine-5-carbonitrile derivatives as anticancer agents targeting EGFRWT and EGFRT790M," Organic and Biomolecular Chemistry, vol. 18, no. 38, pp. 7608-7634, 2020.

[39] M. I. Youssef, Y. Zhou, I. H. Eissa et al., "Tetradecyl 2,3dihydroxybenzoate alleviates oligodendrocyte damage following chronic cerebral hypoperfusion through IGF-1 receptor," Neurochemistry International, vol. 138, Article ID 104749, 2020. 